\title{
Microstructure Evolution and Solidification Cracking in Austenitic Stainless Steel Welds
}

\author{
Using a novel quenching technique to simultaneously reveal \\ microstructure evolution and induce cracking, a new fundamental \\ understanding of solidification cracking was gained
}

BY P. YU, K. J. THOMPSON, J. McCARTHY, AND S. KOU

\begin{abstract}
Two austenitic stainless steels representing different resistance to solidification cracking were investigated: 304 , which solidifies as $\delta$-ferrite dendrites (bcc), and 310 , which solidifies as austenite $\gamma$ dendrites (fcc). They were quenched during gas tungsten arc welding with liquid Wood's metal (at $75^{\circ} \mathrm{C}$ ). Quenching induced much more cracking in 310 than 304 , consistent with the much higher crack susceptibility of 310 observed in conventional solidification cracking tests. In 304 , the $L+\delta+\gamma$ reaction consumed interdendritic liquid ( $L$ ) and formed $\gamma$ continuously between $\delta$-ferrite dendrites, bonding the dendrites together to resist cracking. In 310 , the $L+\delta+\gamma$ reaction did not form continuous $\delta$-ferrite to bond $\gamma$ dendrites together to resist cracking, and the $\gamma$ dendrites were coarse with long, straight boundaries to make cracking easy to occur. The well-known room-temperature microstructure consisting of vermicular/lacy $\delta$-ferrite in a matrix of $\gamma$, which often exists in welds of austenitic stainless steels with good crack resistance (such as 304 ), was not found in the mushy zone, neither in 304 nor 310 . This microstructure, though widely used to explain the crack resistance, cannot resist cracking because it does not even exist in the mushy zone, where solidification cracking occurs during welding. The present study demonstrated that, to understand solidification cracking in austenitic stainless steels, revealing the elevated-temperature microstructure of the mushy zone during welding is much more useful than examining the room-temperature microstructure of the fusion zone after welding.
\end{abstract}

\section{KEYWORDS}

- Solidification Cracking • Austenitic Stainless Steel

- Alloy 304 • Alloy 310 • Microstructural Evolution

- Gas Tungsten Arc Welding

\section{Introduction}

Austenitic stainless steels are known to be susceptible to solidification cracking, cracking that occurs inside the mushy zone during welding and leaves behind open cracks in the fusion zone of the resultant weld. The mushy zone is a weak semisolid region immediately behind the advancing weld pool (Ref. 1). According to Novikov (Ref. 2), cracking during solidification is caused by obstructed shrinkage. The higher density of the solid metal than the liquid metal causes the solidifying mushy zone to shrink. For instance, solid aluminum is $6.6 \%$ higher in density than liquid aluminum (Refs. 3, 4). The thermal expansion coefficient of metals also causes the solidifying mushy zone to shrink, but to a lesser extent. However, the mushy zone cannot shrink freely because it is connected to the workpiece, which is much bigger and more rigid than the mushy zone. Tight clamping of the workpiece can make it worse. Obstructed shrinkage can induce significant tension in the lateral direction of the mushy zone to cause cracking. Cracking occurs along grain boundaries during the terminal stage of solidification, where a small amount of liquid remains along grain boundaries, enough to keep grains from bonding together but not enough to fill the intergranular space (i.e., crack) formed when the grains are separated under tension.

\section{Solidification Cracking of Austenitic Stainless Steels}

Various factors affecting the crack susceptibility of austenitic stainless steels have been investigated (Refs. 5-11). In general, as shown by Masumoto et al. (Ref. 6), austenitic stainless steels tend to be less susceptible to solidification cracking if the primary solidification phase (the first solid to form from the liquid) is $\delta$-ferrite (bcc) instead of austenite $\gamma(\mathrm{fcc})$. The widely cited review of Shankar et al. (Ref. 5) summarized many factors that have been proposed 


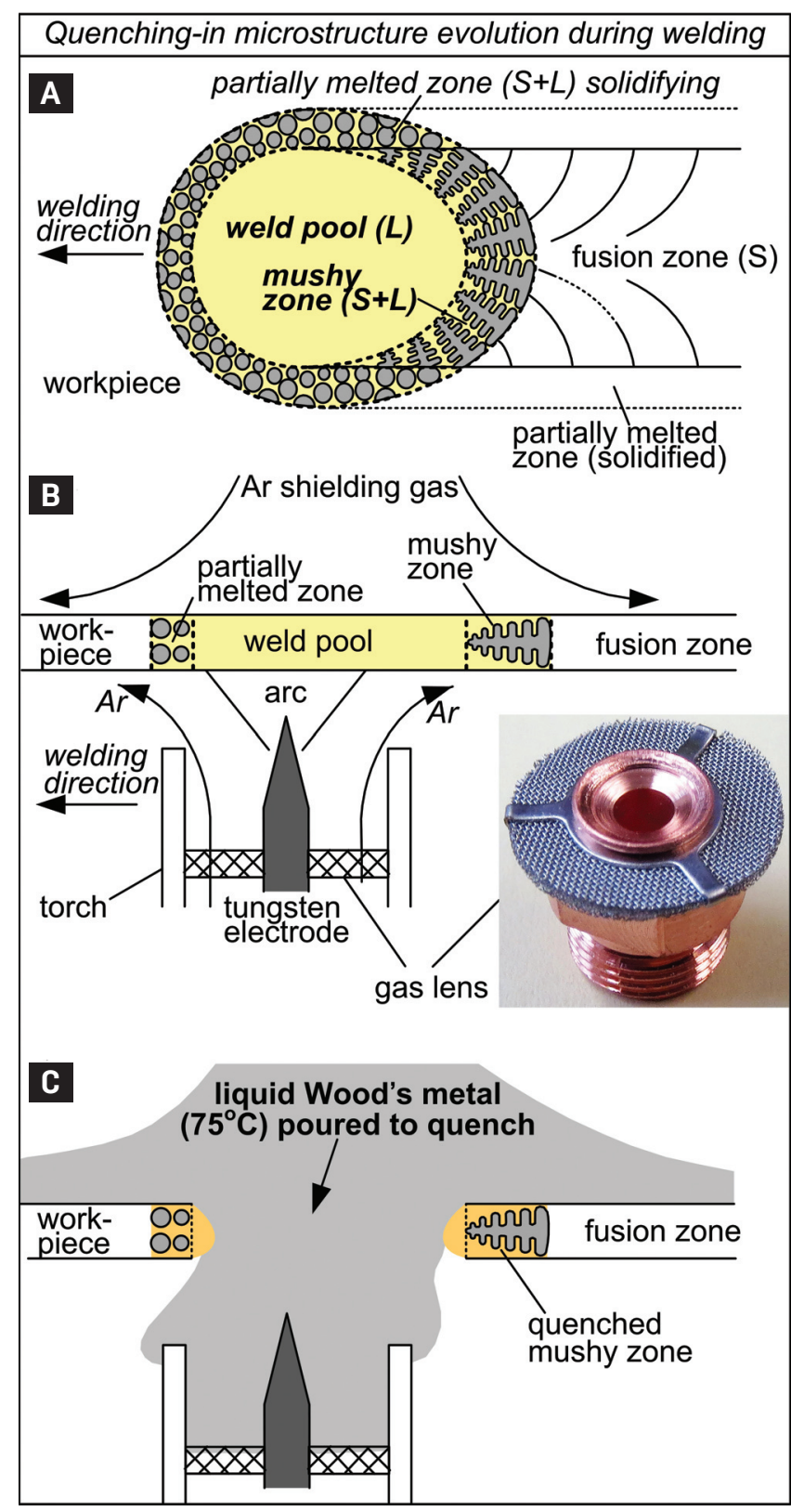

Fig. 1-A novel technique for quenching during welding: A - Top view of weld pool and surroundings; $B$ - side view; $C$ - quenching weld pool surroundings. Welding from below the workpiece makes room for quenching. Gas lens keeps liquid Wood's metal from entering the torch. Wood's metal $\left(70^{\circ} \mathrm{C}\right.$ melting point) can be poured from a glass beaker and separated from the quenched workpiece and gas lens in hot water after welding.

to explain the beneficial effect of $\delta$-ferrite on the cracking behavior (Refs. 12-18).

\section{Bonding between Grains to Resist Solidification Cracking}

Kou's solidification model (Refs. 19, 20) showed the earlier dendrites bond together during solidification, the higher the resistance to solidification cracking. Liu and Kou (Refs.
21-25) further showed in $\mathrm{Al}$ alloys, backdiffusion during solidification (e.g., $\mathrm{Mg}$ in $\mathrm{Al}-4 \mathrm{Mg}$ alloy) can cause earlier bonding between dendrites and increase the resistance to cracking. Bonding between growing grains can also play a significant role in the solidification cracking of austenitic stainless steels, as will be shown subsequently. However, unlike in $\mathrm{Al}$ alloys, it can be affected significantly by the $L+\delta+\gamma$ reaction during solidification.

\section{Quenching Stainless Steels with Sn}

Ice-water quenching of stainless steel during welding does not work well because steam and bubbles prevent effective heat transfer between water and stainless steel. So, Kou and Le (Ref. 26) first used liquid Sn to quench stainless steels during welding. Sn quenching worked much better than ice-water quenching and was also used by subsequent investigators to study phase transformations in stainless steels during welding (Refs. 27, 28). Matsuda et al. (Ref. 9) used Sn quenching to study solidification cracking in stainless steels. This is the only solidification cracking study known to the authors that revealed the mushy-zone microstructure.

\section{Experimental Procedure}

\section{A Novel Quenching Technique for Welding}

To further improve quenching, Wood's metal was used to quench stainless steels during welding. It is a eutectic alloy of $50 \% \mathrm{Bi}, 26.7 \% \mathrm{~Pb}, 13.3 \% \mathrm{Sn}$, and $10 \% \mathrm{Cd}$ by weight (Ref. 29). Like $\mathrm{Ga}$ or In, it melts at a very low temperature $\left(70^{\circ} \mathrm{C}\right)$ but is much less expensive. Because of the lower pouring temperature of Wood's metal $\left(75^{\circ} \mathrm{C}\right)$ than $\mathrm{Sn}\left(300^{\circ} \mathrm{C}\right)$, Wood's metal quenching was much easier to conduct and significantly more effective than $\mathrm{Sn}$ quenching. It revealed the microstructure more clearly and induced cracking more easily.

Figure $1 \mathrm{~A}$ is a top view showing the weld pool and the mushy zone behind it during the welding of an alloy (Ref. 1). Figure $1 \mathrm{~B}$ is a vertical cross section (through the weld centerline and the axis of the tungsten electrode) showing the position of the welding arc relative to the weld pool and the mushy zone. Welding from below the workpiece provided more room for quenching from above. Molten Wood's metal was poured onto the weld pool and its surroundings to quench the mushy zone behind it, as illustrated in Fig. 1C. The arc was turned off immediately after quenching. The torch continued to travel for 2 to $3 \mathrm{~s}$ before it was stopped. For comparison, welding was also conducted under identical conditions without quenching.

About $50 \mathrm{~mL}$ of liquid Wood's metal was held in a 100$\mathrm{mL}$ Pyrex glass beaker and poured at $75^{\circ} \mathrm{C}$. With an ordinary glove, the glass beaker can be picked up directly to pour without using crucible tongs. After welding, the solidified Wood's metal was separated from the workpiece by heating in hot water. This quenching technique was recently tried on $\mathrm{Al}$ alloys (Ref. 25) because liquid $\mathrm{Sn}$ is too warm for quenching Al. No elements in Wood's metal were detected in the $\mathrm{Al}$ welds. Wood's metal quenching was further improved in the present study, including the use of a gas lens to keep the 


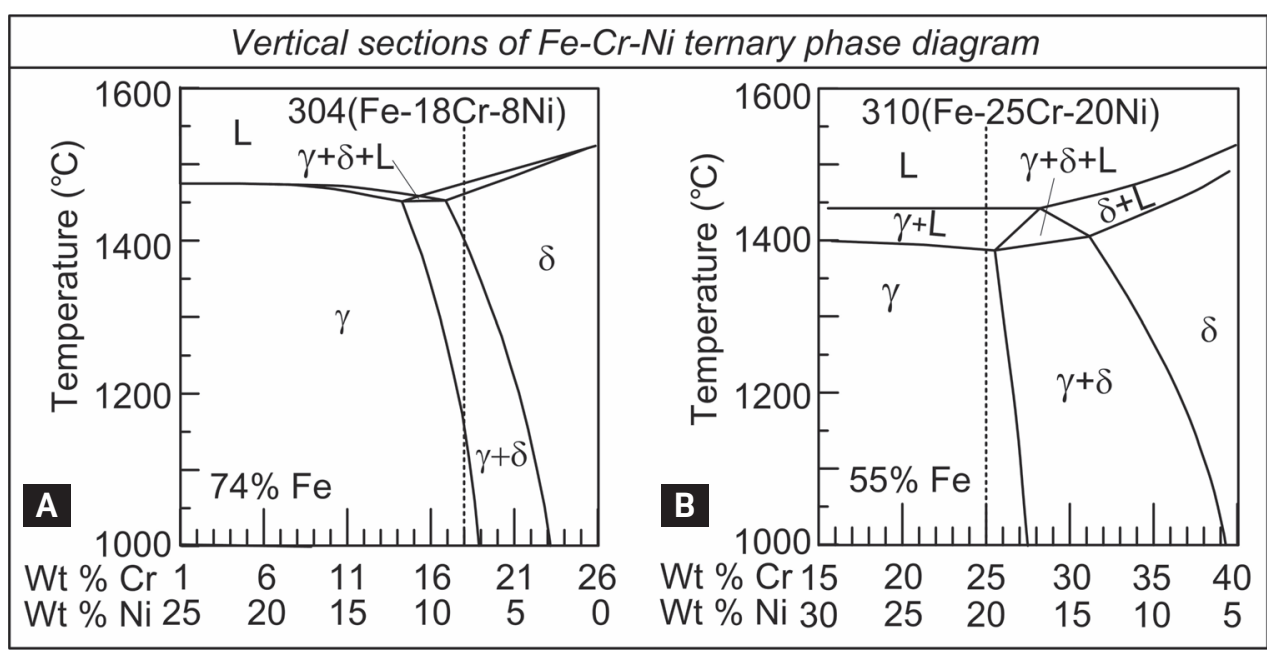

Fig. 2 - Vertical sections of ternary Fe-Cr-Ni phase diagram: A - Fe-18Cr-8Ni (close to 304 stainless steel), which solidifies as primary $\delta$-ferrite (Ref. 34); B - Fe-25Cr-20Ni (close to 310 stainless steel), which solidifies as primary austenite $\gamma$ (Ref. 35). etched. In-situ x-ray diffraction by synchrotron radiation, pioneered by Elmer (Ref. 30) for studying phase transformations during welding, is an advanced technique. However, Wood's metal quenching is simple and inexpensive enough to be used in any welding lab. An additional advantage is that it can induce solidification cracking as well as reveal microstructural evolution during welding.

The composition analysis was conducted by an electron probe microanalyzer (EPMA). SXFiveFE, a state-of-the-art field emission EPMA for quantitative analysis and $\mathrm{x}$-ray mapping at high spatial resolution, was used (Ref. 31). Wavelength dispersive spectrometers (WDS), up to five, could be fitted

Wood's metal from entering and damaging the torch. Since the Wood's metal could be separated from the gas lens in hot water, the same gas lens was used over and over again.

The chemical compositions of the 304 and 310 stainless steels used are shown in Table 1 . The workpiece was 102 $\mathrm{mm}$ (4 in.) long, $51 \mathrm{~mm}$ (2 in.) wide, and $1.6 \mathrm{~mm}$ (1/16 in.) thick. Bead-on-plate gas tungsten arc welding without a filler metal was conducted in the length direction of the workpiece along its centerline. Direct current electrode negative (DCEN) was used with Ar shielding. The torch travel speed was 1.35 to $1.48 \mathrm{~mm} / \mathrm{s}$ (3.2 to $3.5 \mathrm{in} . / \mathrm{min}$ ), the welding current was 48 to $55 \mathrm{~A}$, and the voltage was 7.8 to $10 \mathrm{~V}$. The arc length was initially set at $2.3 \mathrm{~mm}$.

\section{Analysis of Welds}

The resultant welds were cut, polished, and electrochemically etched with a solution consisting of $60 \mathrm{~g}$ of oxalic acid in $600 \mathrm{~mL}$ of water. For 304 stainless steel, the voltage was $10 \mathrm{~V}$ and the etching time $15 \mathrm{~s}$. For 310 stainless steel, the voltage was $5 \mathrm{~V}$ and the etching time $7 \mathrm{~s}$. Mixed acids were also used for etching, consisting of $10 \mathrm{~mL} \mathrm{HNO}_{3}, 20 \mathrm{~mL}$ $\mathrm{HCl}$, and $30 \mathrm{~mL} \mathrm{H}_{2} \mathrm{O}$. The etched samples were examined by optical microscopy, with or without differential interference contrast (DIC), and scanning electron microscopy (SEM). The phases present in the microstructure were identified by electron backscatter diffraction (EBSD). This was conducted using a Thermo Scientific Quasor EBSD installed on a JEOL JSM-7001F scanning electron microscope at Thermo Fisher Scientific in Fitchburg, Wis. The samples were sequentially hand polished down to a 20-nm colloidal slurry but not into the microprobe for high-precision quantitative analysis. The beam was fully focused with an approximate diameter of $80-100 \mathrm{~nm}$. The voltage and current were $8 \mathrm{kV}$ and $20 \mathrm{nA}$, respectively. The volume below the sample surface affected by the beam was about $250 \mathrm{~nm}$ in diameter (Refs. 32, 33). The samples were polished and very lightly etched.

\section{Results and Discussion}

For convenience of discussion, the vertical sections of the ternary $\mathrm{Fe}-\mathrm{Cr}-\mathrm{Ni}$ phase diagram are shown at $74 \mathrm{wt}-\% \mathrm{Fe}$ in Fig. 2A for $304(\sim \mathrm{Fe}-18 \mathrm{Cr}-8 \mathrm{Ni}$ ) (Ref. 34 ) and at $55 \mathrm{wt}-\% \mathrm{Fe}$ $(\sim \mathrm{Fe}-25 \mathrm{Cr}-20 \mathrm{Ni})$ in Fig. 2B for 310 (Ref. 35). They show 304 solidifies as primary $\delta$ and transforms to $\gamma$ upon further cooling after solidification, while 310 solidifies as primary $\gamma$ without postsolidification phase transformation.

\section{Welds Made without Quenching}

Figure 3A shows the fusion-zone microstructure of an unquenched 304 weld that was electroetched. It consists of a thin dark-etching $\delta$-ferrite in a light-etching matrix of austenite $\gamma$, either vermicular (also called skeletal) ferrite or lacy ferrite. Figure 3B shows the fusion-zone microstructure of an unquenched 310 weld that was etched with mixed acids. The micrograph, taken with DIC, shows light-etching $\gamma$ dendrites and some dark-etching $\delta$-ferrite. Unlike in Fig. $3 \mathrm{~A}, \delta$-ferrite is absent from most areas occupied by $\gamma$. A minimum of about $5 \%$ $\delta$-ferrite is usually considered as a requirement for a weld of austenitic stainless steel to resist solidification cracking.

Table 1 - Chemical Compositions of Stainless Steels Used in the Present Study (in wt-\%)

\begin{tabular}{ccccccccccc} 
& $\mathrm{C} \%$ & $\mathrm{Cr} \%$ & $\mathrm{Ni} \%$ & $\mathrm{Mn} \%$ & $\mathrm{Si} \%$ & $\mathrm{Cu} \%$ & $\mathrm{Mo} \%$ & $\mathrm{~N} \%$ & $\mathrm{P} \%$ & $\mathrm{~S} \%$ \\
\hline 304 & 0.055 & 18.17 & 8.07 & 1.00 & 0.045 & - & - & 0.048 & 0.031 & 0.002 \\
310 & 0.05 & 25.55 & 19.22 & 0.84 & 0.57 & 0.22 & 0.25 & 0.0 & 0.02 & 0.001 \\
\hline
\end{tabular}




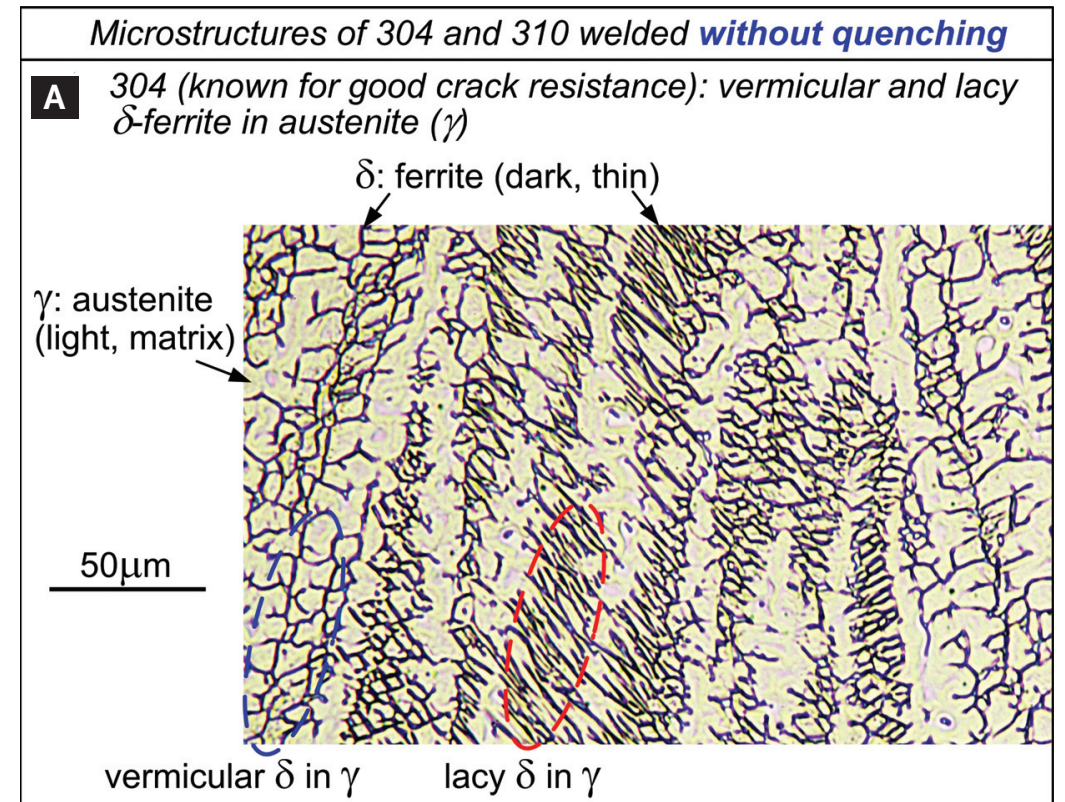

B 310 (known for poor crack resistance): no vermicular or lacy $\delta$-ferrite in austenite $(\gamma)$

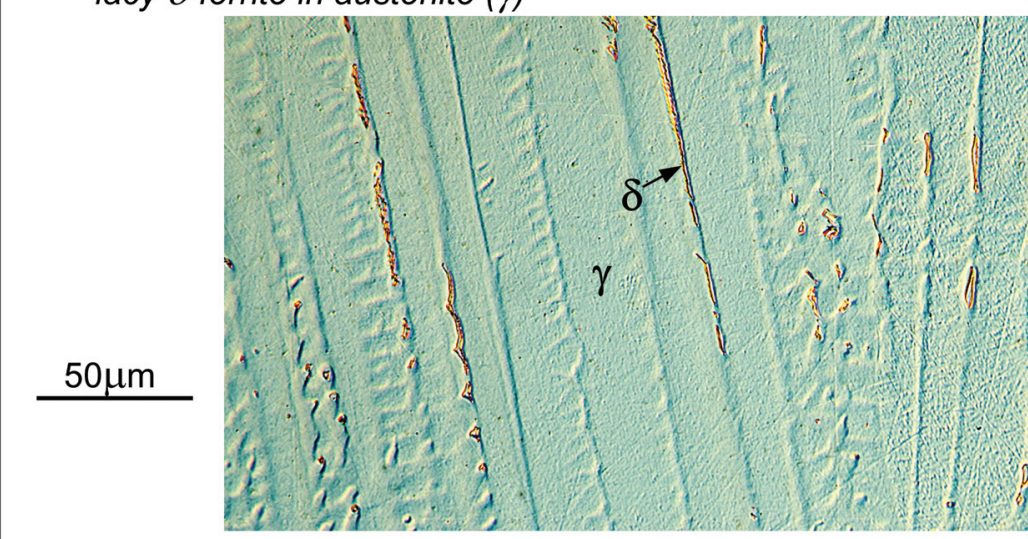

C Factors proposed to explain why microstructure consisting of vermicular/lacy $\delta$ in $\gamma$ resists solidification cracking:

1. Irregular crack path caused by vermicular/lacy $\delta$ present in $\gamma$,

2. Interface energy of $\delta / \gamma<$ interface energy of $\gamma / \gamma$ or $\delta / \delta$,

3. Very fine structure (due to grain refining by vermicular/lacy $\delta$ ),

4. Large $\delta / \gamma$ interface area to disperse sulfur $(S)$, phosphorus $(P)$,

5 . Less tensile stresses ( $\delta \rightarrow \gamma$ transformation decreases volume),

6. Less grain-boundary S/P (S/P dissolved more in $\delta$ than $\gamma$ ),

7. Less thermal stresses ( $\delta$ more ductile than $\gamma$ ),

8. Less thermal stresses (less thermal expansion in $\delta$ than $\gamma$ ),

9. Faster S/P homogenization (faster diffusion in $\delta$ than in $\gamma$ ).

Fig. 3 - The $\delta$-ferrite content in welds of austenitic stainless steels: $A-$ 304 showing vermicular/lacy $\delta$ in $\gamma ; B-310$ showing a little $\delta$ but not vermicular/lacy $\delta$; $C$-factors explaining the beneficial effect of microstructure consisting of vermicular/lacy $\delta$ in $\gamma$, summarized from the review by Shankar et al. (Ref. 5).
Since 304 stainless steel is known to resist solidification cracking much better than 310 (Ref. 1 ), Fig. $3 A$ and B suggest the microstructure of vermicular/lacy $\delta$ in $\gamma$ is associated with the good resistance to solidification cracking. In fact, the room-temperature, fusion-zone microstructure of vermicular/lacy $\delta$ in $\gamma$ has been widely used to explain the crack resistance of austenitic stainless steels (Ref. 5). To the best knowledge of the authors, the elevated-temperature, mushy-zone microstructure has not been shown so far in studies on solidification cracking of stainless steels, except for that by Matsuda et al. (Ref. 9) using Snquenching. Figure $3 \mathrm{C}$ summarizes the factors that have been proposed to explain the beneficial effect of the microstructure of vermicular/lacy $\delta$ in $\gamma$ on reducing solidification cracking (Refs. 5, 12-18).

\section{Solidification Cracking}

Figure 4 shows a 304 stainless steel weld quenched and electroetched. As shown by Fig. 4A, most of the liquid in the weld pool was pushed out by Wood's metal during quenching. Figure $4 \mathrm{~B}$ shows the mushy zone. Solidification cracking occurs mainly in three different areas, as shown in Fig. 4C-E. Columnar dendrites of the primary solidification phase $\delta$-ferrite are clear in the mushy zone. Cracking occurs mainly along boundaries between dendrites, typical of solidification cracking. The quenched pool boundary, that is, the beginning of the mushy zone, is indicated by a white broken line. A dark broken line indicates the beginning of the postsolidification $\delta \rightarrow \gamma$ phase transformation. It forms $\gamma$ along boundaries between $\delta$-ferrite dendrites. In Fig. 4D, the distance between the two broken lines is $225 \mu \mathrm{m}$, i.e., the maximum possible width of the mushy zone. The main crack runs across the entire width of the mushy zone and propagates slightly beyond it.

\section{Identification of Phases in $\mathbf{3 0 4}$ Mushy Zone}

Figure 5 shows a 304 weld quenched and etched with mixed acids, which reveal $\gamma$ in the 304 mushy zone more clearly than electroetching. The sample was prepared for electron beam backscatter diffraction (EBSD) without etching. After EBSD, it was etched with mixed acids and then photographed. The micrograph in Fig. 5B is located in the middle of the mushy zone, away from the pool boundary. The broken line indicates the beginning of $\gamma$ formation by the $\delta \rightarrow \gamma$ phase transformation after solidification.

The microstructure in the white box in Fig. 5B is enlarged in Fig. 5C, and the corresponding EBSD map is shown in Fig. 5D. The green areas in Fig. 5D indicate $\delta$-ferrite (bcc), and they correspond to the main bodies of the $\delta$-ferrite den- 


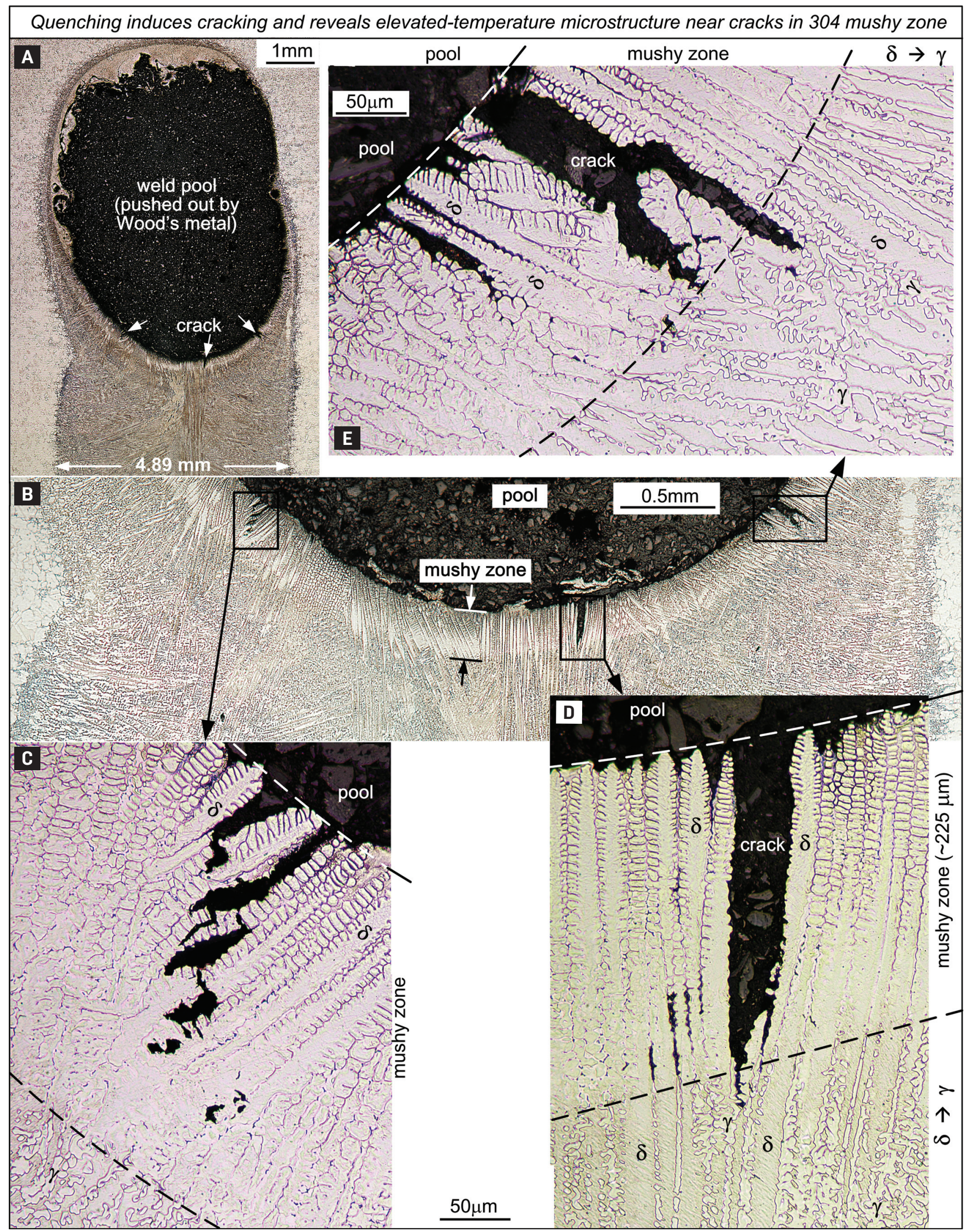

Fig. 4 - Mushy zone microstructure of a 304 weld quenched and electroetched: $A$ - Macrograph; B - mushy zone; C, D, E - microstructure near cracks. 


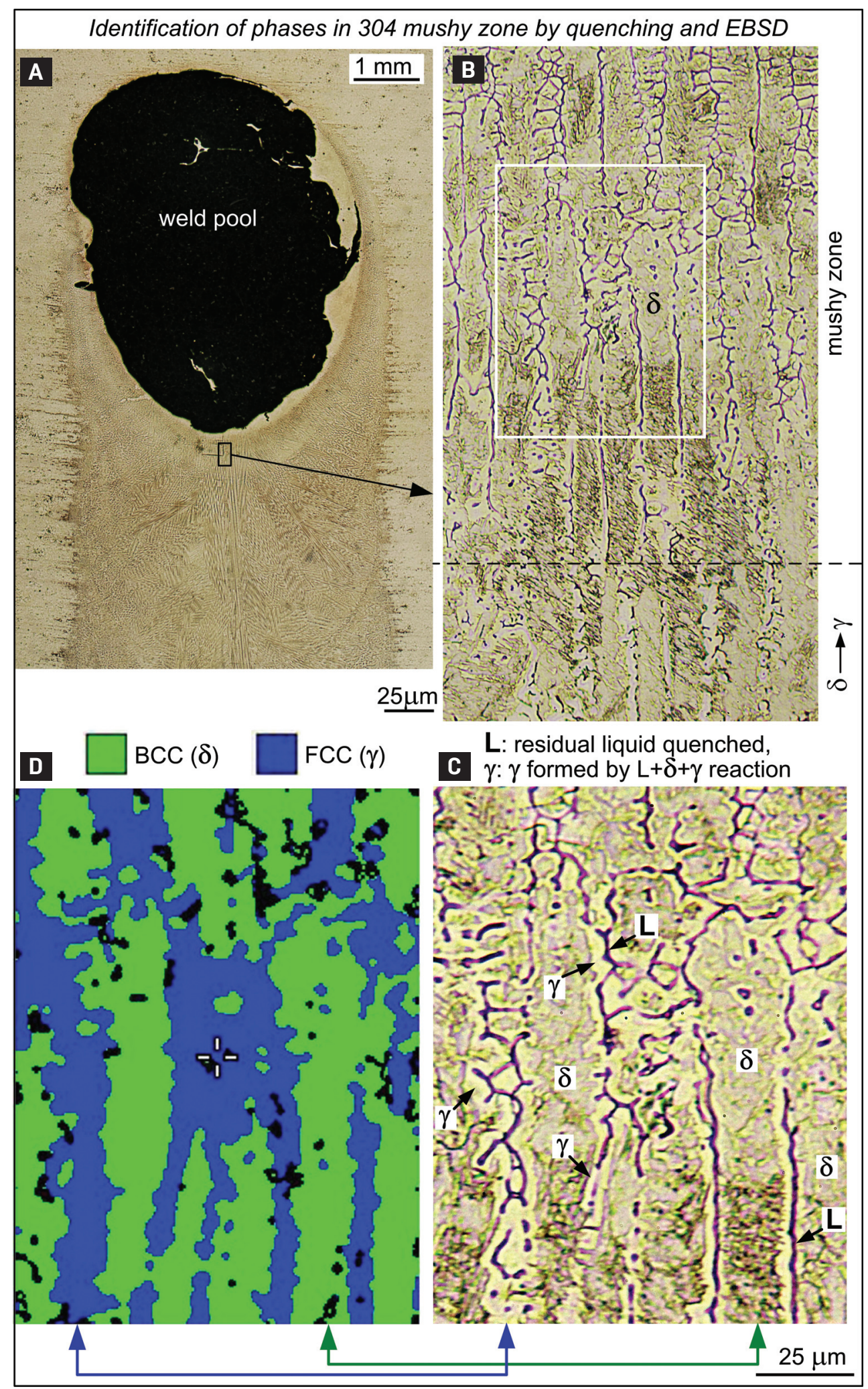

Fig. 5 - Phases in the 304 mushy zone (etched with mixed acids): A - Macrograph; B - micrograph in the boxed area in $A ; C$ - micrograph enlarged, showing $\gamma$ that formed along the boundaries between $\delta$-ferrite dendrites during the $L+\gamma+\delta$ stage of solidification and residual liquid (purple, richer in $\mathrm{Cr}$ and $\mathrm{Ni}$ ) that solidified upon quenching; $\mathrm{D}-\mathrm{EBSD}$ map of $\mathrm{C}$. drites in Fig. 5C. The blue areas in Fig. 5D, on the other hand, indicate austenite $\gamma(\mathrm{fcc})$. This suggests the presence of $\gamma$ along the boundaries between the $\delta$-ferrite dendrites. As can be seen in Fig. $5 C$, austenite $\gamma$ exists along the boundaries between $\delta$-ferrite dendrites and is light yellow in color. This is the $\gamma$ that forms during the $L+\delta+\gamma$ stage of solidification. The thin purple phase in $\gamma$ is the residual liquid during the $L+\delta+\gamma$ stage of solidification that was quenched. Fu et al. (Refs. 36-38) identified by TEM the phases in a 304 stainless steel that was quenched in water during directional solidification in an $\mathrm{Al}_{2} \mathrm{O}_{3}$ tube. They also showed grain boundary $\gamma$ and quenched residual liquid in $\gamma$.

Figure 6 shows the compositions of the phases in the 304 mushy zone determined by EPMA. As shown, the three phases differ in the Ni content. The $\mathrm{Ni}$ content is lowest in $\delta$-ferrite ( 7 wt-\%), higher in $\gamma(\sim 8$ wt$\%)$, and highest in the quenched residual liquid ( 9-11 wt-\%). In the studies by Fu et al. (Refs. 36-38), the Ni content was also lowest in $\delta$-ferrite $(F)$, higher in $\gamma$ (A) and highest in the quenched residual liquid (L).

\section{Microstructure Evolution}

Figure 7A shows a 304 weld quenched and electroetched, about $4 \mathrm{~mm}$ wide. The microstructure in the rectangular box is shown in Fig. 7B and continued in Fig. 7C. As shown, microstructure evolution begins with primary solidification $\mathrm{L} \rightarrow$ $\delta$, that is, $\delta$-ferrite dendrites growing at the weld pool boundary, which is indicated by the upper broken line in Fig. 7B. The $\mathrm{L}+\delta+\gamma$ reaction is next. In the boxed areas in Fig. 7B, evidence of this three-phase reaction can be seen, as will be shown subsequently in Figs. 8 and 9. As indicated by the two broken lines in Fig. 7B, the mushy zone is at most $275 \mu \mathrm{m}$ wide. The postsolidification $\delta \rightarrow \gamma$ transformation 


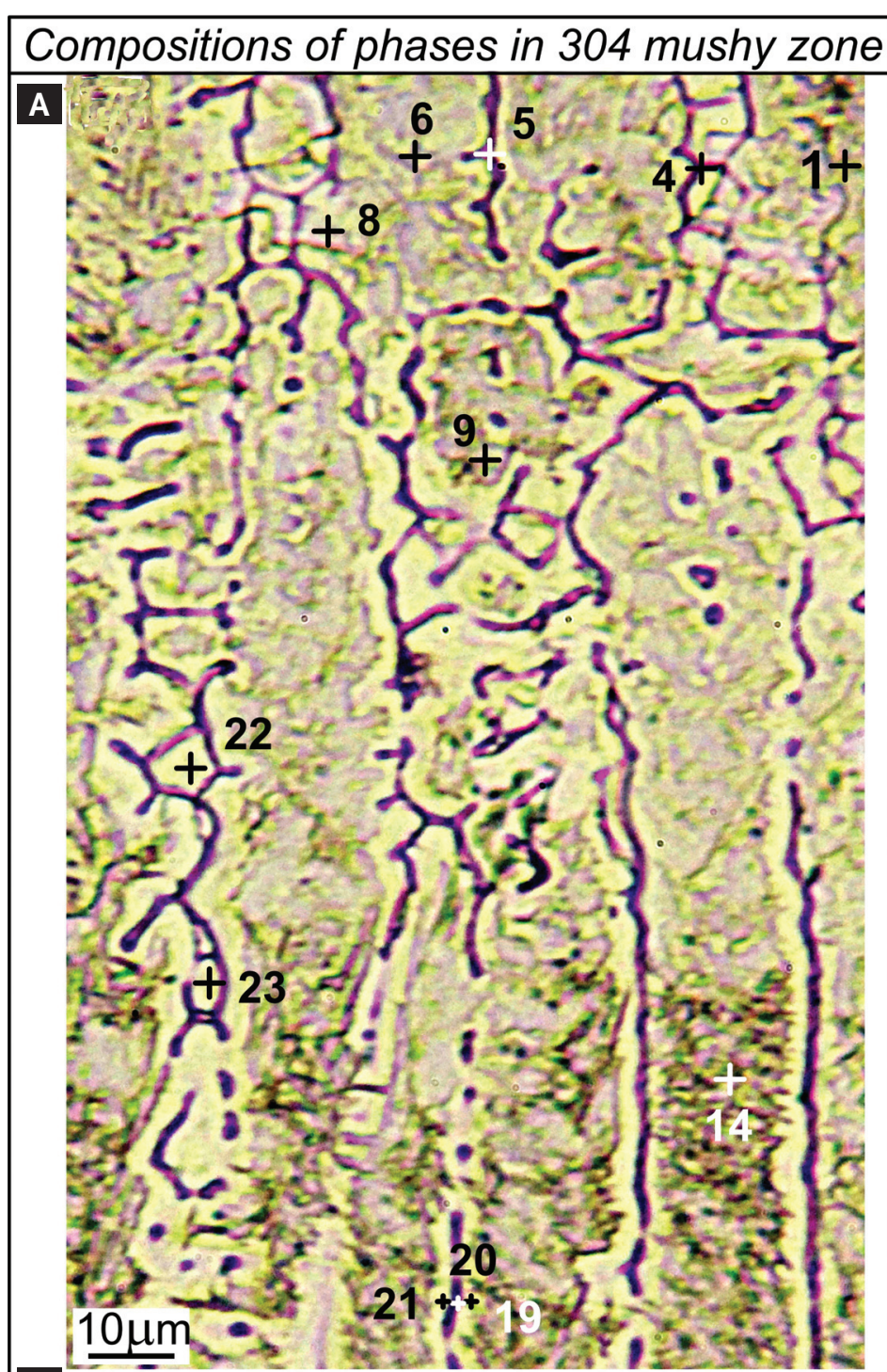

B

\begin{tabular}{|cccccc|}
\hline \# & $\mathrm{Cr}(\mathrm{wt} \%)$ & $\mathrm{Ni}(\mathrm{wt} \%)$ & $\mathrm{Mn}(\mathrm{wt} \%)$ & $\mathrm{Fe}$ & Phase \\
\hline 1 & 17.28 & 7.03 & 1.06 & balance & $\mathrm{F}$ \\
\hline 6 & 17.25 & 7.09 & 1.15 & balance & $\mathrm{F}$ \\
\hline 9 & 17.66 & 7.22 & 1.25 & balance & $\mathrm{F}$ \\
\hline 14 & 18.11 & 6.87 & 1.22 & balance & $\mathrm{F}$ \\
\hline \hline 8 & 17.56 & 8.36 & 1.50 & balance & $\mathrm{A}$ \\
\hline 19 & 17.70 & 8.00 & 1.24 & balance & $\mathrm{A}$ \\
\hline 21 & 17.21 & 8.52 & 1.12 & balance & $\mathrm{A}$ \\
\hline 22 & 17.83 & 8.53 & 1.24 & balance & $\mathrm{A}$ \\
\hline 23 & 17.43 & 7.97 & 1.29 & balance & $\mathrm{A}$ \\
\hline \hline 4 & 17.70 & 9.52 & 1.53 & balance & $\mathrm{L}$ \\
\hline 5 & 17.15 & 9.09 & 1.44 & balance & $\mathrm{L}$ \\
\hline 20 & 18.33 & 11.57 & 1.57 & balance & $\mathrm{L}$ \\
\hline
\end{tabular}

Fig. 6-Compositions of phases in the 304 mushy zone determined by electron probe microanalysis (EPMA): $A$ - Locations of measurements; $B$ - measured compositions. is the next microstructure evolution. The $\delta$-ferrite dendrites begin to transform to $\gamma$ (lower broken line). Eventually, only a small amount of $\delta$-ferrite is left, either as vermicular or lacy ferrite as can be seen in Fig. 7D, which is located far behind the end of Fig. 7C. This microstructure is similar to that in the un-quenched weld in Fig. $3 \mathrm{~A}$. This indicates that the well-known microstructure of vermicular/lacy $\delta$-ferrite in $\gamma$ does not exist in the mushy zone during welding but forms in the fusion zone after solidification is over. Thus, it cannot resist solidification cracking as often suggested.

Before leaving this section, it is perhaps worth mentioning that near the bottom of Fig. 7C, some $\gamma$ appears to grow into neighboring $\delta$-ferrite at an angle similar to the angle of the $\gamma$ in the lacy ferrite in Fig. 7D. According to Inoue et al. (Ref. 28), if the Kurdjumov-Sachs orientation relationships, i.e., $(-110)_{\delta} / /(-111)_{\gamma}$ and $[-1-11]_{\delta} / /[-1-10]_{\gamma}$, exist between $\delta$-ferrite and $\gamma$, the $\delta$ - $\gamma$ transformation occurs along the $\gamma$ habit plane into $\delta$-ferrite dendrites. Otherwise, vermicular ferrite can form.

\section{Crack Resistance}

According to Fig. 2A, $\gamma$ can form when the threephase triangle $\mathrm{L}+\delta+\gamma$ is reached during solidification. Both peritectic reaction and eutectic reaction have been proposed for austenitic stainless steels (Refs. 28, 37). The peritectic reaction is $\mathrm{L}+\delta \rightarrow \gamma$ and the eutectic reaction $\mathrm{L} \rightarrow \delta+\gamma$. However, it is not the intention of the present study to determine which reaction occurs. For convenience of discussion, both reactions will be called the $\mathrm{L}+\delta+\gamma$ reaction. Fu et al. (Refs. 36-38) observed coupled $\delta / \gamma$ growth from undercooled liquid.

Figure 8 shows some dendrites in the middle of Fig. 7B. Between the two thick arrowheads is a grain boundary between two columnar dendritic grains of $\delta$-ferrite. The $\mathrm{L}+\delta+\gamma$ reaction causes $\gamma$ (light-etching) to form continuously along the grain boundary. This grainboundary $\gamma$ divides and surrounds the grain boundary liquid L (dark etching). The upper thick arrowhead is not far behind the tips of the dendrites. This suggests the grains are bonded together early during solidification to resist solidification cracking.

The mushy-zone microstructure in the two dotted boxes in Fig. 7B is enlarged in Fig. 9A, B. Two distinct phases are visible along the grain boundary. The lighteretching continuous phase is $\gamma$, and the darker-etching discontinuous phase (gold or brown in color) is the quenched residual liquid. This microstructure is consistent with Fig. 5C, which shows $\gamma$ and residual liquid coexist along the boundaries between $\delta$-ferrite dendrites. The simultaneous presence of $\mathrm{L}, \delta$, and $\gamma$ indicates the $\mathrm{L}$ $+\delta+\gamma$ reaction.

The SEM images of the microstructure in the boxed areas in Fig. 9A and B are shown in Fig. 9C and D, respectively. Continuous $\gamma$ forms along boundaries of $\delta$-ferrite dendrites to bond them together and divide/surround the residual liquid, which appears to be etched out as holes or grooves during electroetching. In the SEM image of a 304 stainless steel quenched during directional solidification and electroetched with oxalic acid, $\gamma$ also 
appeared smooth, and the quenched residual liquid was also etched out as holes or grooves (Refs. 36-38).

\section{Stainless Steel}

Figure 10 shows a quenched 310 weld in which the phases present were identified by EBSD. The weld was electroetched, and the macrograph is shown in Fig. 10A. As shown, significant cracking was induced by quenching, much more cracking than in the 304 welds. This is consistent with the much higher crack susceptibility of 310 than 304 observed in conventional crack susceptibility tests (Refs. 39, 40). Thus, Wood's-metal quenching can discriminate the solidification cracking susceptibility between different alloys. However, the big crack along the centerline, about $1.2 \mathrm{~mm}$ long, is obviously longer than the centerline of the mushy zone. In other words, this solidification crack propagates not just through the entire mushy zone but further into the fusion zone as a ductility-dip crack. Also, 310 stainless steel is known to be susceptible to ductilitydip cracking as well as solidification cracking (Refs. 41, 42). Ductility-dip cracking in stainless steels, however, is beyond the scope of the present study.

As mentioned previously, EBSD was conducted without etching. After EBSD the sample was etched with mixed acids to reveal $\delta$-ferrite. Figure 10B shows the mushy-zone microstructure in the upper boxed area near the weld pool in Fig. 10A. Figure 10C shows the EBSD maps of the boxed area in Fig. 10B. Except for a few small dots, the entire area is $\gamma(\mathrm{fcc})$. Thus, near the pool boundary the mushy zone microstructure is mainly dendrites of $\gamma$. This confirms the primary- $\gamma$ solidification mode of 310 stainless steel, consistent with Fig. 2B. The dominating crystal orientation (represented by red color) is $\langle 001\rangle$, which is the easy growth direction of fcc metals. The microstructure in the lower boxed area in Fig. 10A is shown in Fig. 10D, whose EBSD map is shown in Fig. 10E. Thus, the fusionzone microstructure consists of $\delta$-ferrite in a matrix of $\gamma$. This $\delta$-ferrite forms by the $L+\gamma+\delta$ reaction. According to Fig. 2B, there is no $\gamma \rightarrow \delta$ postsolidification phase transformation in 310 to form $\delta$-ferrite from $\gamma$.

Figure 11A shows a 310 weld quenched and etched with mixed acids, again showing significant cracking. As compared to electro etching, etching with mixed acids reveals $\delta$-ferrite more clearly but the macrostructure of the weld less clearly. The microstructure in the rectangular box is shown in Fig. 11B and continued in Fig. 11C. To also include some of the den- drites growing from the side toward the centerline of the mushy zone, Fig. $11 C$ was taken by first shifting somewhat to the right. As shown by Fig. 11B, many primary dendrite arms (about a dozen) grow in the same direction. They belong to the same grain that grows essentially along the welding direction. This indicates $\gamma$ dendrites tend to form coarse grains with long, straight grain boundaries as shown more clearly in Fig. $10 \mathrm{~A}$ by electroetching. These grains can promote solidification cracking because long, straight grain boundaries are easy for liquid to remain continuous and for cracks to propagate.

In Fig. 11B, the location where liquid films disappear is taken as the end of the mushy zone and marked with a broken line. This is because the mushy zone, by definition, is the region where solid and liquid both exist during solidification. The mushy zone is about $440 \mu \mathrm{m}$ wide. This is significantly wider than the 304 mushy zone shown previously in Fig. 7B, which is at most $275 \mu \mathrm{m}$ wide. The wider mushy zone of 310 


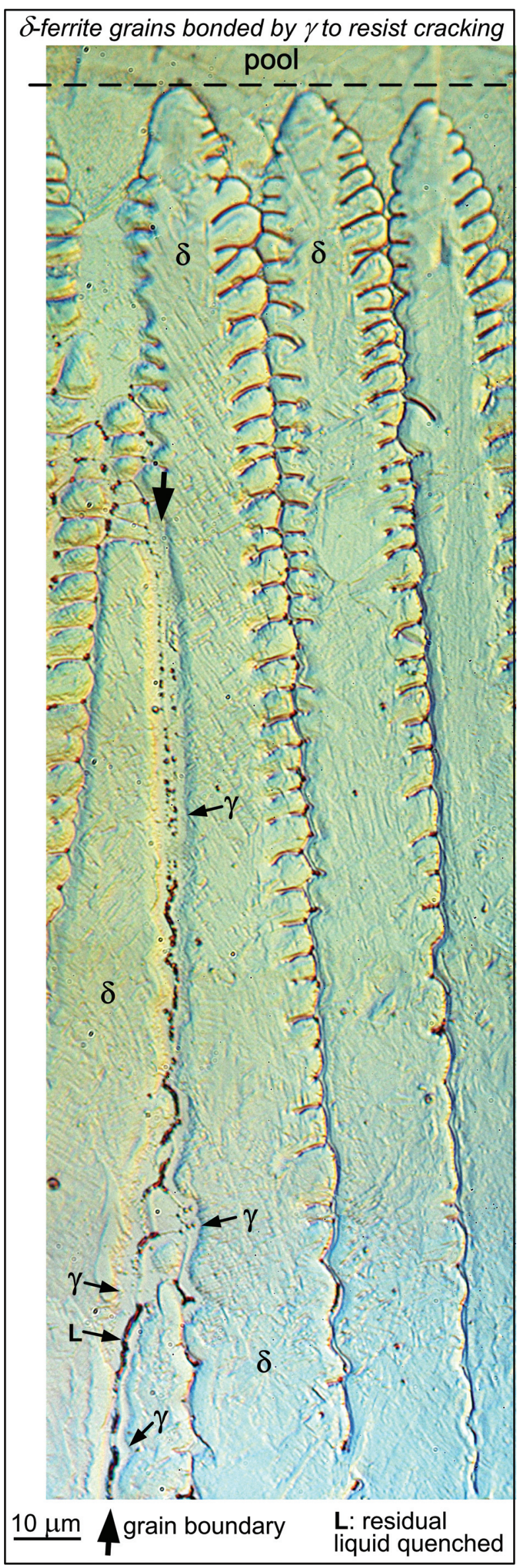

may also contribute to its higher crack susceptibility than 304 . Figure 11D shows the fusion-zone microstructure far behind the box in Fig. 11A. Its similarity to that in Fig. $11 \mathrm{C}$ suggests no postsolidification phase transformation, consistent with the vertical section shown in Fig. 2B. It is also similar to that in the 310 weld made without quenching - Fig. 3B.

Figure 12A shows the microstructure in the boxed area in Fig. 11B. The residual quenched liquid (L) indicates liquid films are present along boundaries of $\gamma$ dendrites, which are enlarged in in the SEM image in Fig. 12C. Sometimes, Wood's metal might touch a long, continuous liquid film. Fig. 12B is the microstructure in the boxed area in Fig. 11C, showing elongated $\delta$-ferrite particles along boundaries of $\gamma$ dendrites, which are enlarged in the SEM image in Fig. 12D.

The microstructure evolution shown in Fig. 11 indicates that the $\mathrm{L}+\gamma+\delta$ reaction does not form continuous $\delta$-ferrite to bond $\gamma$ dendrites together or consume interdendritic liquid enough to make it discontinuous. Thus, the $L+\gamma+\delta$ reaction cannot help 310 reduce the high crack susceptibility caused by its coarse $\gamma$ dendrites with long, straight boundaries. This explains its high crack susceptibility.

\section{New Explanations for Crack Resistance vs. Old}

Figure 13 summarizes the explanations for the resistance to solidification cracking observed in welds of 304 and 310 . Based on the elevated-temperature microstructure of the mushy zone revealed by quenching, the new explanation for the good crack resistance of 304 stainless steel is shown in Fig. 13A. It includes 1$)$ the $L+\delta+\gamma$ reaction in 304 forms continuous $\gamma$ along boundaries between $\delta$ dendrites to bond them together early during solidification, and consumes interdendritic liquid to make it discontinuous, and 2) the mushy zone is narrow.

The new explanation for the much worse crack resistance of 310 stainless steel, as shown in Fig. 13B, includes 1) the $\mathrm{L}+\delta+\gamma$ reaction in 310 neither forms continuous $\delta$ along boundaries between $\gamma$ dendrites to bond them together nor consumes interdendritic liquid significantly to make it discontinuous; 2) coarse $\gamma$ dendrites with long, straight boundaries help residual liquid remains as continuous films and cracks propagate; and 3 ) the mushy zone is significantly wider in 310 than 304.

The old explanations, on the other hand, are based on the room-temperature microstructure of the fusion zone (Refs. 5, 12-18). As shown by Fig. 13C, a microstructure consisting of vermicular/lacy $\delta$ in a $\gamma$ matrix (Fig. 3A) is believed to resist cracking well. However, Wood's metal quenching showed such a microstructure does not even exist in the mushy zone (Figs. 7B and 4C, E), where solidification cracking occurs. Thus, even though such a microstructure can correlate well with good crack resistance (Fig. 3A), it cannot explain solidification cracking. As for 310, as shown in Fig. $13 \mathrm{D}$, the old explanation for its poor crack resistance is the absence of such a microstructure.

Before closing, it should be mentioned that the results of the present study do not necessarily contradict the constitu-

Fig. 8 - The $\delta$-dendrites in Fig. $7 B$ enlarged to show $L+\gamma+\delta$ reaction forms continuous $\gamma$ to bond $\delta$-grains along the grain boundary (between two thick arrowheads) and divide liquid $L$ to resist cracking. 


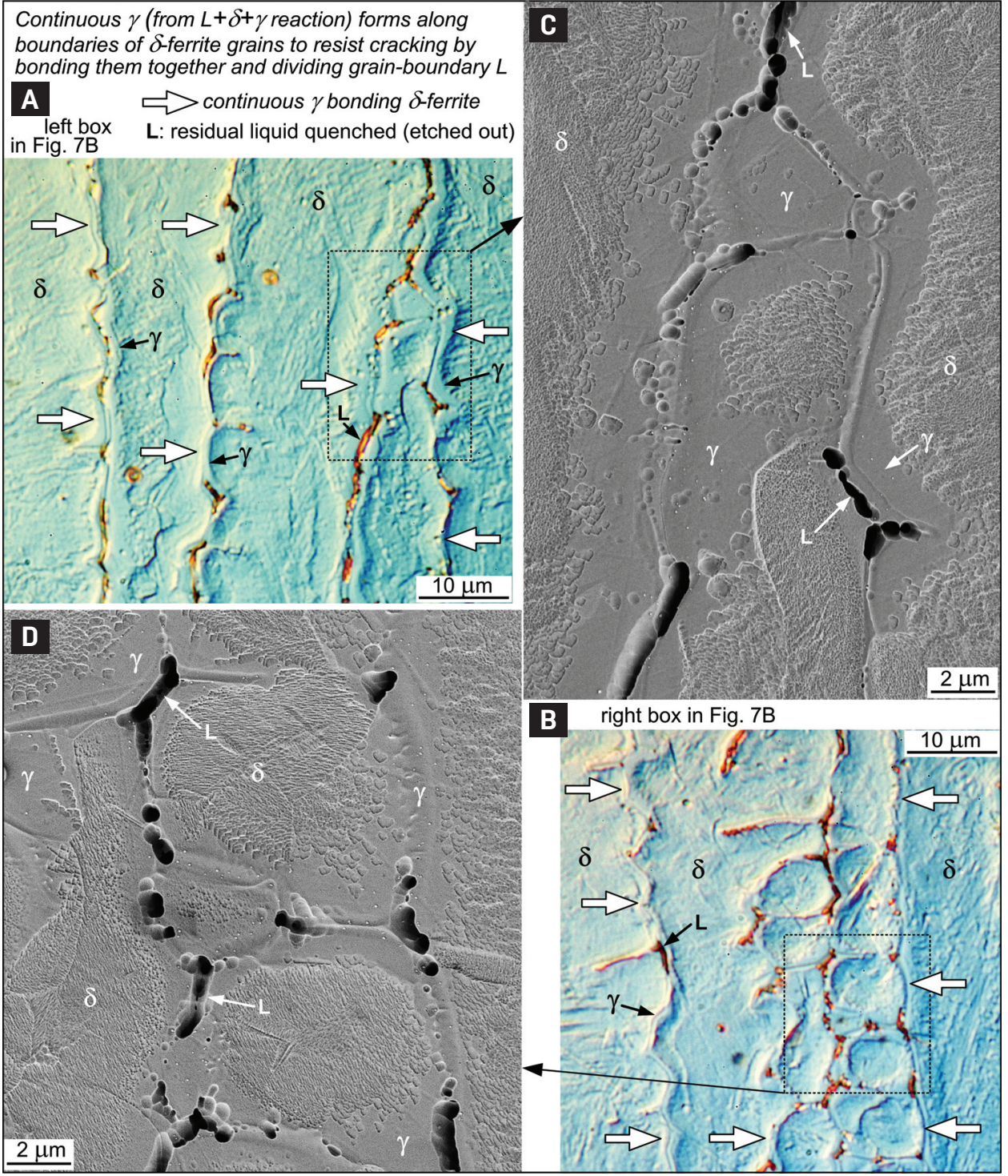

Fig. $9-$ Bonding of $\delta$-ferrite grains in the 304 mushy zone by $\gamma$ to resist cracking, which forms along grain boundaries by $L+\gamma+\delta$ reaction (electroetched): $A-L$ eft boxed area in Fig. $7 B ; B-$ right boxed area in Fig. $7 B ; C, D-S E M$ image of boxes in $A, B$. cracking by forming continuous $\gamma$ to bond $\delta$-ferrite dendrites together early during solidification and consuming the interdendritic liquid to make it less continuous and hence less able to separate the dendrites.

3 . As shown by the quenched welds of 304, the well-known microstructure consisting of vermicular/lacy $\delta$-ferrite in a $\gamma$ matrix forms in the fusion zone after solidification is over - not in the mushy zone during welding. This microstructure (Fig. 3A), though widely used to explain the crack resistance of welds of austenitic stainless steels such as 304, cannot explain the crack resistance as widely believed because it does not even exist in the mushy zone, where solidification cracking occurs during welding.

4. In 310 , the $L+\delta+\gamma$ reaction neither forms continuous $\delta$-ferrite to bond $\gamma$ dendrites together nor consumes the interdendritic liquid enough to make it discontinuous. To make it worse, the $\gamma$ dendrites are often coarse with long, straight boundaries to help liquid films remain continuous and cracks propagate.

5. Wood's metal quenching can induce much more cracking in 310 than 304, consistent with results of conventional crack susceptibility tests.

6. The EPMA composition measurements in the $L+\gamma+\delta$ region of the quenched 304 mushy zone showed the Ni content is lowest in $\delta$-ferrite (about $7 \mathrm{wt}-\%$ ), higher in $\gamma$ (about 8 wt \%), and highest in the quenched residual tion diagrams, such as Schaeffler's diagram (Ref. 43) or the WRC-1992 diagram (Ref. 45). These diagrams are empirical data that correlate the solidification modes and the compositions of the weld metals. The effect of the solidification modes on the solidification cracking susceptibility suggested by the constitution diagrams can still be consistent with that observed in the present study.

\section{Conclusions}

1. Wood's metal quenching can be a useful novel technique for studying solidification cracking in austenitic stainless steel welds. It can reveal microstructure evolution and induce cracking simultaneously to show the microstructure effect on cracking. The elevated-temperature mushy-zone microstructure, though essential for understanding solidification cracking, is almost never shown in solidification cracking studies.

2. In 304 , the $L+\delta+\gamma$ reaction helps resist solidification liquid (about 9-11 wt-\%).

\section{Acknowledgments}

This work was supported by the National Science Foundation under Grant No. DMR 1500367 and the University of Wisconsin Foundation. The authors thank Dr. John Fournelle of the Department of Geoscience, the University of Wisconsin, Madison, Wis., for composition measurements by EPMA.

\section{References}

1. Kou, S. 2013. Welding Metallurgy, $2^{\text {nd }}$ edition. Hoboken, N.J.: John Wiley \& Sons. pp. 257, 263-300.

2. Novikov, I. I. April 1962. Alloying non-ferrous alloys to reduce 


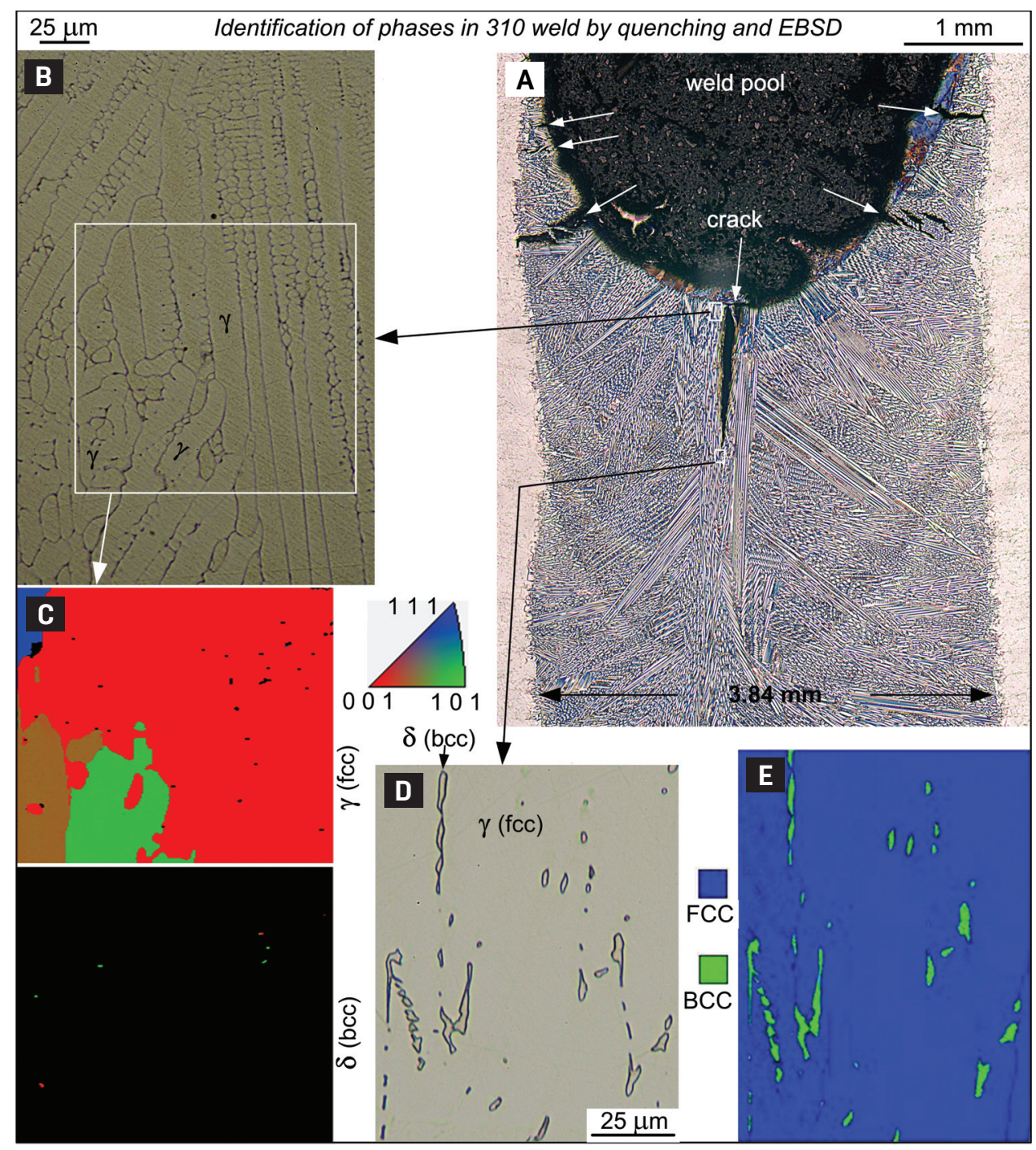

Fig. 10 - Identification of phases in the 310 weld: A - Macrograph, electroetched; B mushy zone microstructure near the weld pool, etched with mixed acids; $C$ - EBSD corresponding to the boxed the area in B, showing $\gamma(f c c)$ matrix and very small $\delta(b c c)$ particles; $D-$ microstructure in fusion zone, etched with mixed acids; $E-E B S D$ corresponding to $D$.
Welds III. Berlin, Germany: SpringerVerlag. pp. 131-144.

11. Tate, S. B., Javernick, D. A., Lienert, T. J., and Liu, S. 2016. Laser weldability of $21 \mathrm{Cr}-6 \mathrm{Ni}-9 \mathrm{Mn}$ stainless steel: Part I — Impurity effects and solidification mode. Welding Journal 95(10): 371-s to 383-s.

12. Borland, J. C., and Younger, R. N. 1960. Some aspects of cracking in welded $\mathrm{Cr}$-Ni austenitic steels. British Welding Journal 7(1): 22-59.

13. Matsuda, F., Nakagawa, H., Uehara, T., Katayama, S., and Arata, Y. 1979. A new explanation for role of delta-ferrite improving weld solidification crack susceptibility in austenitic stainless steel (materials, metallurgy, weldability). Transactions of JWRI 8(1): 105-112.

14. Hull, F. C. 1967. Effect of delta ferrite on the hot cracking of stainless steel. Welding Journal 46(9): 399-s to 409-s.

15. Pellini, W. S. 1952. Strain theory of hot tearing. Foundry 80(11): 125-133.

16. Brooks, J. A., Thompson, A. W., and Williams, J. C. 1984. A fundamental study of the beneficial effects of delta ferrite in reducing weld cracking. Welding Journal 63(3): 71-s to 83-s.

17. Kujanpaa, V. P. 1985. Effect of steel type and impurities in solidification cracking of austenitic stainless steel welds. Metal Construction 17(1): 40R-46R.

18. Thier, H., Killing, R., and Killing, U. 1987. Solidification modes of weldments in corrosion resistant steels How to make them visible. Metal Construction 19: 127-130.

19. Kou, S. 2015. A criterion for cracking during solidification. Acta Materialia 88: 366-374. DOI: 10.1016/j. actamat.2015.01.034

20. Kou, S. 2015. A simple index for hot tearing. Russian Castings Production: 167-172.

3. Flemings, M. C. 1974. Solidification Processing. New York, N.Y.: McGraw-Hill. pp. 252-256, and Appendix B.

4. Campbell, J. 2003. Castings, $2^{\text {nd }}$ ed. Oxford, UK: Butterworth Heinemann. p. 242.

5. Shankar, V., Gill, T. P. S., Mannan, S. L., and Sundaresan, S. 2003. Solidification cracking in austenitic stainless steel welds. Sadhana 28(3-4): 359-382.

6. Masumoto, I., Tamaki, K., and Kutsuna, M. 1972. Hot cracking of austenitic stainless steel weld metal. Transactions of Japan Welding Society 41(11): 1306-1314.

7. David, S. A., Goodwin, G. M., and Braski, D. N. 1979. Solidification behavior of austenitic stainless steel filler metals. Welding Journal 58(11): 330-s to 336-s.

8. Elmer, J. W., Allen, S. M., and Eagar, T. W. 1989. Microstructural development during solidification of stainless steel alloys. Metallurgical and Materials Transactions A 20(10): 2117-2131.

9. Matsuda, F., Nakagawa, H., and Lee, J. 1987. Weld cracking in duplex stainless steel (Report I). Trans. JWRI 16(2): 343-349.

10. Cross, C. E., Coniglio, N., Westin, E. M., and Gumenyuk, A. 2011. Laser weldability of stainless steel. Hot Cracking Phenomena in predicting the susceptibility to solidification cracking. Welding Journal 94(12): 374-s to 388-s.

21. Liu, J., and Kou, S. 2015. Effect of diffusion on susceptibility to cracking during solidification. Acta Materialia 100: 359-368. DOI: 10.1016/j.actamat.2015.08.064

22. Liu, J., and Kou, S. 2016. Crack susceptibility of binary aluminum alloys: Analytical equations. Shape Casting: $6^{\text {th }}$ International Symposium. Springer. DOI: 10.1007/978-3-319-48166-1

23. Liu, J., and Kou, S. 2016. Crack susceptibility of binary aluminum alloys during solidification. Acta Materialia 110: 84-94. DOI: 10.1016/j.actamat.2016.03.030

24. Liu, J., and Kou, S. 2017. Susceptibility of ternary aluminum alloys to cracking during solidification. Acta Materialia 125: 513-523. DOI: 10.1016/j.actamat.2016.12.028

25. Liu, J., Duarte, H. P., and Kou, S. 2017. Evidence of back diffusion reducing cracking during solidification. Acta Materialia 122: 47-59. DOI: 10.1016/j.actamat.2016.09.037

26. Kou, S., and Le, Y. 1982. The effect of quenching on the solidification structure and transformation behavior of stainless steel welds. Metallurgical and Materials Transactions A 13(7): 1141-1152. 


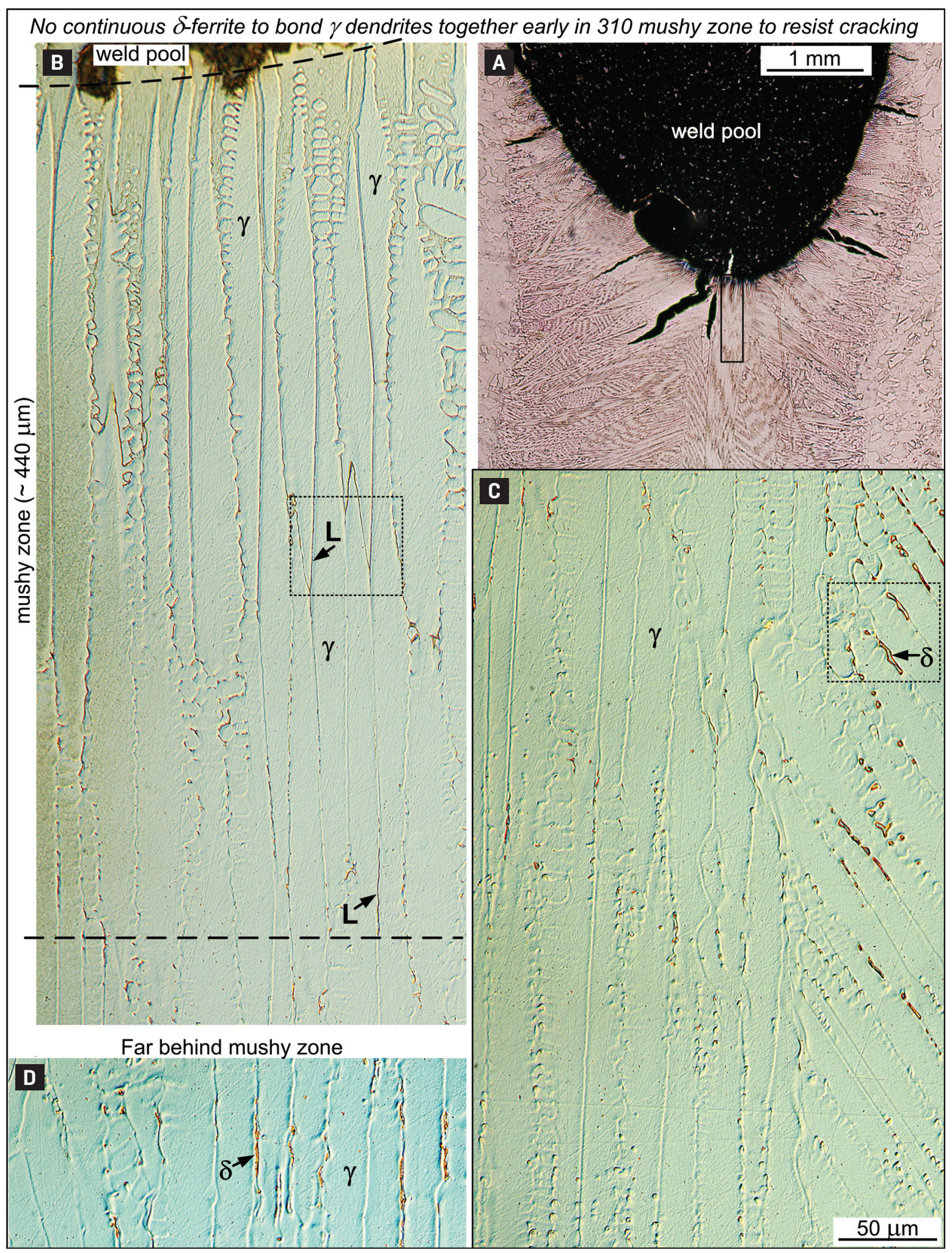

Fig. 11 - Microstructural evolution in a 310 weld quenched and etched with mixed acids: A - Macrograph; B mushy zone; $C$ - continuation from bottom of B; D - far behind mushy zone and $C$, still showing $\delta$ in the interdendritic space between $\gamma$ dendrites, i.e., no evidence of postsolidification phase transformation. Compare with 304 in Fig. 7. 


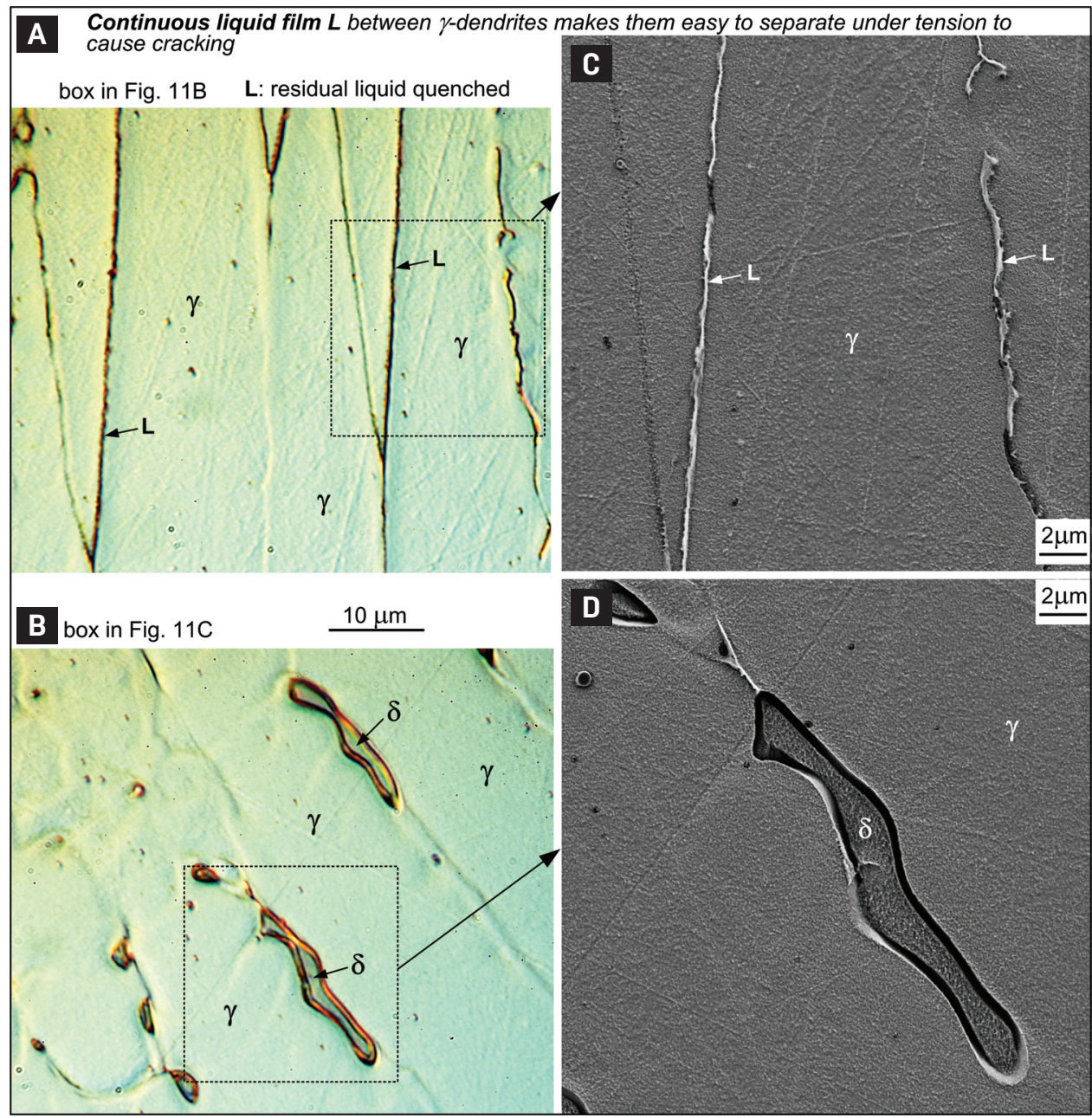

Fig. 12 - Quenched microstructure of 310: A - Micrograph in boxed area in Fig. 118, showing continuous liquid along boundaries between $\gamma$ dendrites in the middle of the mushy zone, which prevents bonding between $\gamma$ dendrites to resist cracking; $B$ - micrograph in the boxed area in Fig. IIC; $C$ - SEM image in boxed area in $A ; D-S E M$ image in the boxed area in $B$. Compare with Fig. 9 for 304.

27. Inoue, H., Koseki, T., Ohkita, S., and Fuji, M. 2000. Formation mechanism of vermicular and lacy ferrite in austenitic stainless steel weld metals. Science and Technology of Welding and Joining 5(6): 385-396. DOI: 10.1179/136217100101538452

28. Inoue, H., Koseki, T., Okita, S., and Fuji, M. 1997. Solidification and transformation behaviour of austenitic stainless steel weld metals solidified as primary ferrite: Study of solidification and subsequent transformation of $\mathrm{Cr}$-Ni stainless steel weld metals ( ${ }^{\text {nd }}$ Report). Welding International 11(12): 937-949. DOI: 10.1080/ 09507119709447349

29. Gardner's Chemical Synonyms and Trade Names. New York, N.Y.: John Wiley \& Sons.

30. Elmer, J. W., Wong, J., and Ressler, T. 2000. In-situ observations of phase transformations during solidification and cooling of austenitic stainless steel welds using time-resolved x-ray diffraction. Scripta Materialia 43(8): 751-757. DOI: 10.1016/S1359-6462(00)00481-4

31. CAMECA SXFiveFE: Field Emission Electron Probe Microanalyser. cameca.com/instruments-for-research/sxfivefe.aspx.

32. Fournelle, J. H. 2016.Private communications. Department of Geoscience, University of Wisconsin, Madison, Wis.

33. Yu, P., Chai, X., Landwehr, D., and Kou, S. 2016. Ni-WC hardfacing by gas metal arc welding. Welding Journal 95: 451-s to 466-s.
34. Hillert, M., and Qiu, C. 1990. A reassessment of the $\mathrm{Cr}-\mathrm{Fe}-\mathrm{Ni}$ system. Metallurgical Transactions A 21(6): 1673-1680.

35. Lippold, J. C., and Savage, W. F. 1979. Solidification of austenitic stainless steel weldments. Welding Journal 58(12): 362-s to 374-s.

36. Fu, J. W., Yang, Y. S., Guo, J. J., Ma, J. C., and Tong, W. H. 2009. Formation of two-phase coupled microstructure in AISI 304 stainless steel during directional solidification. Journal of Materials Research 24(7): 2835-2840. DOI: 10.1557/jmr.2009.0282

37. Fu, J. W., and Yang, Y. S. 2013. Origin of the lathy ferrite in AISI 304 stainless steel during directional solidification. Journal of Alloys and Compounds 580: 191-194. DOI: 10.1016/j.jallcom. 2013.05.107

38. Fu, J., Sun, J., Cen, X., Zhang, X., Li, F., and Wu, Y. 2018. Growth behavior and orientation relationships in AISI 304 stainless steel during directional solidification. Materials Characterization 139: 241-248. DOI: 10.1016/j.matchar.2018.03.015

39. Lippold, J. C., and Savage, W. F. 1982. Solidification of austenitic stainless steel weldments: Part III — The effect of solidification behavior on hot cracking susceptibility. Welding Journal 61(12): 388-s to 396-s.

40. Senda, T., Matsuda, F., Takano, G., Watanabe, K., Kobayashi, T., and Matsuzaka, T. 1971. Fundamental investigations on solidi- 


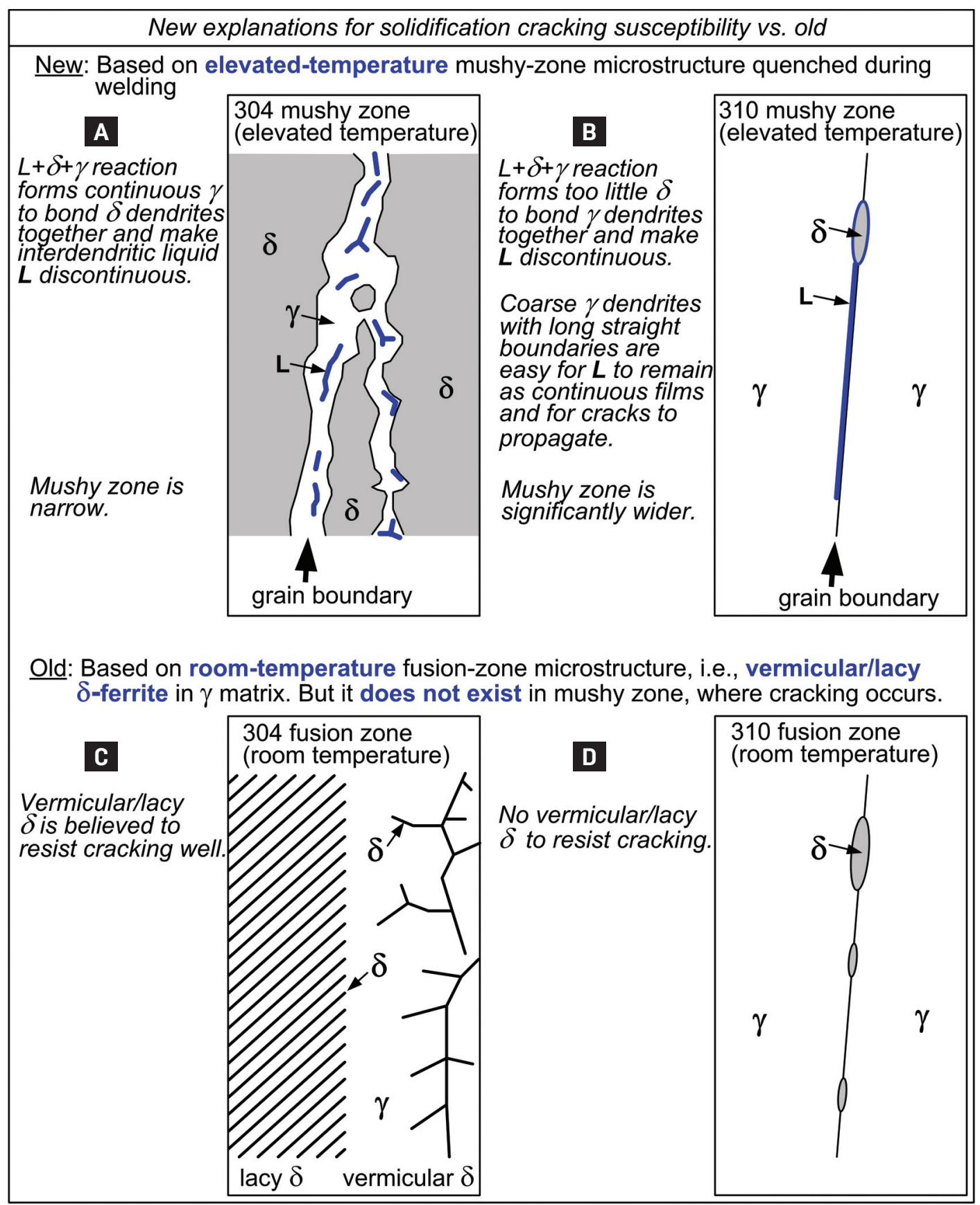

Fig. 13 - Summary of explanations for much better resistance of 304 stainless steel to solidification cracking than 310: A, B - New explanations; C, D - old.

fication crack susceptibility for weld metals with Trans-Varestraint test. Transactions of the Japan Welding Society 2(2): 141-162.

41. Lippold, J. C. 2014. Welding Metallurgy and Weldability. Hoboken, N.J.: John Wiley \& Sons.

42. Arata, Y., Matsuda, F., Nakagawa, H., Katayama, S., and Ogata, S. 1977. Solidification crack susceptibility in weld metals of fully austenitic stainless steels (Report III): Effect of strain rate on cracking threshold in weld metal during solidification. Transactions of JWRI 6(2): 197-206.

43. Schaeffler, A. L. 1949. Data sheet 680-B. Metal Progress 56: 680.

44. Kotecki, D. J., and Siewert, T. A. 1992. WRC-1992 constitution diagram for stainless steel weld metals: A modification of the WRC1988 diagram. Welding Journal 71(5): 171-s to 178-s. 